\title{
PAin-RElated FEAR PREDiCTS DisABILITy, BUT NOT PAIN SEVERITY: A PATH ANALYTIC APPROACH OF THE FEAR-AVOIDANCE MODEL
}

Els L.M. Gheldof ${ }^{\mathrm{a}}$, Geert Crombez, ${ }^{\mathrm{b}, *}$, Eva Van den Bussche ${ }^{\mathrm{c}}$, Jan Vinck ${ }^{\mathrm{a}}$, An Van

Nieuwenhuyse $^{\mathrm{d}, \mathrm{e}}$, Guido Moens ${ }^{\mathrm{d}, \mathrm{f}}$, Philippe Mairiaux ${ }^{\mathrm{g}}$, Johan W.S. Vlaeyen ${ }^{\mathrm{h}, \mathrm{i}}$,

a. Research group of Health Psychology, Hasselt University, Belgium

b. Faculty of Psychology \& Educational Sciences, Department of Experimental-Clinical and Health Psychology, Ghent University, Belgium

c. Faculty of Psychology \& Educational Sciences, Catholic University of Leuven - Campus Kortrijk, Belgium

d. Department of Public Health, Section of Occupational, Environmental and Insurance Medicine, Faculty of Medicine, Catholic University of Leuven, Belgium

e. Department of Epidemiology, Scientific Institute of Public Health, Brussels, Belgium

f. Occupational Health Services IDEWE, Leuven, Belgium

g. Department of Occupational Health and Health Education, School of Public Health, University of Liège, Belgium

h. Department of Clinical Psychological Science, Maastricht University, The Netherlands

i. Department of Psychology, University of Leuven, Belgium

* Corresponding author: Tel.: +32-9-2646461, fax: +32-9-2646489. E-mail address:

Geert.Crombez@Ugent.be

Number of text pages: 22; Number of tables: 3; Number of figures: 3

Subject Category: Original article

Keywords: fear-avoidance model, pain, back pain, fear, disability 


\begin{abstract}
Two studies are reported that tested the fear-avoidance (FA) model using path analytic techniques. In Study 1, 429 employees with back pain at baseline and back pain at 18 months follow-up completed questionnaires assessing sociodemographic information, pain severity, negative affect, pain-related fear, and disability. Results indicated that pain severity at baseline predicted pain related fear and disability at follow-up, and that pain-related fear is rather a consequence than an antecedent of pain severity. Results further revealed that the disposition to experience negative affect has a low impact upon pain severity and disability, and is best viewed as a precursor of pain-related fear. Study 2 included 238 employees without back pain at baseline, but who developed back pain at one year follow-up. A similar model as in Study 1 was tested. Overall, results are in line with those of Study 1. Results are discussed in terms of theoretical relevance and clinical implications.
\end{abstract}




\section{INTRODUCTION}

The fear-avoidance (FA) model explains why only a minority of individuals with acute low back pain (LBP) develops chronic pain problems (Vlaeyen et al. 1995; Vlaeyen and Linton 2000). Essentially, it is hypothesized that individuals who become fearful about pain or possible (re)injury, will avoid back-stressing activities and become hypervigilant for their pain. In the long term, this pattern leads to increased disability, physical deconditioning and a low mood. This model has become increasingly popular, and a large body of evidence is in line with its assumptions (Leeuw et al. 2007).

A number of important issues, however, remain unexplored. First, most research supporting the FA model stems from cross-sectional studies with chronic pain patients (Pincus et al. 2002). Some research has extended the FA model to patients with acute LBP (SwinkelsMeewisse et al. 2003; Grotle et al. 2004), but it is still unclear how exactly pain-related fear initiates a vicious circle of more pain and disability. Prospective studies are warranted to address this issue. Second, most studies have used a regression approach in which the unique contribution of several variables in explaining pain and disability is tested (Sieben et al., 2005a, Leeuw et al., 2007b). What is missing is a test of the dynamic and sequential relationships amongst these variables. An analysis of these relationships requires a path analytic or structural equation approach. Few studies have used such an approach (Goubert et al. 2004a; Cook et al. 2006), but both were cross-sectional and do not allow for cause-effect inferences.

We report two independent prospective studies that took into account the above considerations. The aim was to further validate the FA model using a path analytic approach. Participants from both studies were recruited from occupational settings. Study 1 consisted of working employees who experienced LBP at baseline and at follow-up. An a priori model was designed that contained the following ideas. First, both pain-related fear and pain severity at baseline affect pain severity and disability at follow-up. Second, the effects of pain-related fear cannot be equated with the effects of the disposition to experience negative affect (negative affect, NA). At most, NA is a precursor of pain-related fear. We also tested alternative models: whether NA is better conceived of as a consequence instead of as a precursor of pain-related fear and whether pain-related fear is better conceived of as a consequence instead of as an antecedent of pain severity. Study 2 consisted of young working employees who had no back pain at baseline, but developed pain at follow-up. It was not possible to test an identical model as in study 1, because participants did not experience pain 
or pain-associated disability at baseline. However, as in study 1, a similar model was designed and alternative models were tested as well.

\section{STUDY 1}

\section{METHOD}

\section{PARTICIPANTS AND PROCEDURE}

The Euro Back Unit prospective cohort study on the prevention of back pain was used. Details about research objectives, recruitment of participants, and preliminary cross-sectional and prospective results are reported elsewhere (Gheldof et al. 2005; Gheldof et al. 2006; Gheldof et al. 2007). In short, 1294 employees were recruited from 10 companies in Belgium $(n=7)$ and the Netherlands $(n=3)$. At follow-up, 18 months later, valid data were obtained from 812 employees (response rate at follow-up was 63\%).

For this study, the data from the subsample of workers who reported at least 1 day of LBP during the past year both at baseline and at follow-up $(N=527)(89 \%=$ male, mean age $=40.28, S D=7.83$ ) were used. About half of the sample reported a pain duration of less than 30 days in the last year at baseline (51\%). At follow-up, 53\% reported LBP of short term duration, while $47 \%$ experienced LBP of long term duration (longer than 30 days). About $44 \%$ $(\mathrm{n}=199)$ of the participants performed technical work, $42 \%(\mathrm{n}=189)$ performed unskilled labour, and $11 \%(\mathrm{n}=48)$ had an executive function. The remaining $3 \%$ did other work (not further specified in the questionnaire). More than half (58\%) of the participants rated their job as strenuous to very strenuous. More than half (52\%) reported to use physical effort during job activities. About 16\% reported to often kneel while working, $24 \%$ reported to work with the hands above the shoulders, $12 \%$ reported lifting loads exceeding more than $25 \mathrm{~kg}$. About one third (29\%) reported to use vibrating tools, and $57 \%$ reported repetitive movements.

\section{MEASURES}

Participants completed a battery of questionnaires assessing sociodemographic information, negative affect, pain-related fear, pain severity, and disability both at baseline and at 18-months follow up.

Negative affect, the disposition to experience negative affect, was measured using the 
Positive and Negative Affect Scale (PANAS, 20-items; (Watson et al. 1988). This instrument is comprised of two subscales (negative affect and positive affect), each containing 10 items to be rated on a 5-points scale. Items had to be completed while reflecting on the past twelve months. In this study, only the Negative Affect subscale was used. Higher scores reflect higher levels of negative affect. The instrument has appropriate internal consistency and testretest reliability over a 2-month time period, and has adequate convergent and discriminatory validity (Watson et al. 1988).

Pain-related fear was measured by the Dutch version of the Tampa Scale for Kinesiophobia (TSK-AV; (Goubert et al. 2004b; Roelofs et al. 2004), in which the 4 inversed items (items $\mathrm{nr} 4,8,12$, and 16) are omitted. The TSK consists of 13 items with a 4-point scale (range from 'strongly agree' to 'strongly disagree'). Higher scores on the TSK indicate higher levels of fear of (re)injury due to movement. This instrument has a satisfactory reliability and validity (Roelofs et al. 2004).

Pain severity was assessed by three 11-point numeric rating scales (NRS, 1-10), anchored by ' $0=$ no pain' and ' $10=$ worst pain imaginable' (Von Korff et al. 1992). The psychometric properties of this scale are good (Closs et al. 2004). Items relate to the intensity of the worst LBP experience in the past 12 months, the intensity of the average LBP experience in the past 12 months, and the intensity of the current LBP experience. We used the mean sum score of the three scales as index of pain.

Social disability associated with LBP was assessed with the Dutch version of the Pain Disability Index (PDI) (Pollard 1984), which consists of 7 items to be rated on an 11-point NRS (range from ' $0=$ no disability' to ' $10=$ total disability'). This instrument measures the degree to which pain interferes with the performance of social roles in the following 7 areas: family/household responsibilities; recreation (such as hobby, sports, leisure time); social activities; occupation; sexual behaviour; self care; and life support activities (such as eating, sleeping, and breathing). We used a sum score. Higher scores indicate more disability. Results in different chronic pain populations indicate that the PDI is a reliable and valid instrument (Tait et al. 1990).

\section{StATISTICAL ANALYSES}

To investigate the validity of the FA model, we used path analyses [AMOS 5.0] (Arbuckle and Wothke 1995-1999; Arbuckle 2003). The Maximum Likelihood algorithm was used to assess model fit. In line with the recommendations of Bollen and Long (1993) and 
Byrne (2001), several fit indices were used to assess model fit. In the present study, model fit is assessed using the following goodness-of-fit indices: $\chi^{2}$, root mean square error of approximation (RMSEA), goodness-of-fit index (GFI), adjusted goodness-of-fit index (AGFI) comparative fit index (CFI) and the Consistent Akaike Information Criterion (CAIC).

a) $\chi^{2}$ is the most frequently used goodness-of-fit index. A statistically significant $\chi^{2}$ indicates that a significant amount of observed covariance between items remains unexplained by the model, while a non-significant $\chi^{2}$ implies a good fit of the model to the data. This index is sensitive to sample size, which is a disadvantage. In a small sample, a poor fit may result in a non-significant $\chi^{2}$, indicating a good fit. In a large sample, a good fit may result in a significant $\chi^{2}$, indicating a poor fit (Marsch et al. 1988).

b) The RMSEA (Browne and Cudeck 1993) is a fit measure based on population error of approximation. It is unreasonable to assume that the model will hold exactly in the population. Therefore the RMSEA takes into account the error of approximation in the population. A RMSEA value below .05 indicates a close fit and values up to .08 represent reasonable errors of approximation in the population (Browne \& Cudeck, 1993).

c) The GFI and the AGFI (Jöreskog and Sörbom 1984) assess the extent to which the model provides a better fit compared to no model at all. These indices have a range between 0 and 1, with higher values indicating a better fit. A GFI larger than .90 and an AGFI larger than .85 indicate a good fit of the model.

d) The CFI is an incremental fit index (Bentler 1990). It represents the proportionate improvement in model fit by comparing the target model with a baseline model (usually a null model in which all the observed variables are uncorrelated). The CFI ranges between 0 and 1 , with values larger than 90 indicating an adequate fit.

e) The CAIC is a goodness-of-fit measure which adjusts the model's chi-square to penalize for model complexity and sample size (Burnham and Anderson 1998). This measure can be used to compare non-hierarchical as well as hierarchical (nested) models. Lower values on the CAIC measure indicate better fit (Burnham and Anderson 1998).

\section{RESULTS}

PRELIMINARY ANALYSES

We used listwise deletion in case of missing variables; 429 participants had valid 
values on all variables and were included in the path analyses. In Table 1, means, standard deviations, Cronbach's alphas and Pearson's product moment correlations amongst the variables are displayed. Scales were internally consistent with Cronbach's alphas varying from $\alpha=.82$ to $\alpha=.94$. The mean PDI-score at baseline and at follow-up reflect low levels of disability (Pollard 1984). The index of pain severity was high, both at baseline and at followup. Also the means of the TSK were high, indicating a high degree of fear of (re)injury compared to norms for Dutch-speaking CLBP patients (Goubert et al. 2004b). Overall, baseline measures were not significantly different from follow-up measures [except for NA $(t(434)=-2.22, p<.05)$, which increased from baseline to follow-up]. All correlations between variables were significant, varying between .11 and .73 in absolute terms. Overall, correlations were stronger between constructs measured at the same time, as compared to correlations between baseline and follow-up measures. The most pronounced correlations were positive correlations between pain-related fear, pain severity and disability. Lowest correlations were found with NA.

\section{MODEL TESTING}

The initial model (model 1a; see Figure 1S) was a priori designed and based upon theoretical arguments put forward by Vlaeyen and Linton (2000) and results of previous studies (Goubert et al. 2004a; Gheldof et al. 2006). Core ideas were (1) that both pain severity and pain-related fear predict social disability, (2) that pain-related fear predicts pain severity, (3) that NA is a precursor of pain-related fear, and has no strong direct impact upon pain severity and disability.

These relationships were specified for the variables at baseline (t0) and at follow-up (t1). Direct paths were added between the baseline constructs and their respective follow-up variables (e.g., between pain-related fear at baseline and pain-related fear at follow-up). As shown in Table 1S, the results of the path analysis for model 1a resulted in an acceptable goodness-of-fit: $\mathrm{RMSEA}=.06, \mathrm{CFI}=.98, \mathrm{GFI}=.98, \mathrm{AGFI}=.94$ and $\mathrm{CAIC}=192.93$, except for the Chi Square, which was significant, $\chi^{2}(14)=37.58, p<.01$. The standardized path coefficients are presented in Figure 1S. Using these coefficients it is possible to calculate the indirect effects of pain-related fear at baseline ( $\mathrm{t} 0$ ) on pain severity at follow up (t1) and on social disability at follow up (t1). This is done by multiplying the standardized path coefficients along a path that leads from a predictor at baseline to the outcome at follow up (Kline 1998). When there is more than one path, these coefficients are summed. The 
standardized indirect effect of pain-related fear (t0) on pain severity (t1) was $.29(.55 \times .21+$ $.32 \times .53)$. The standardized indirect effect of pain-related fear ( $\mathrm{t} 0)$ on social disability ( $\mathrm{t} 1)$ was .41 . The standardized indirect effect of pain severity ( $\mathrm{t} 0)$ on disability ( $\mathrm{t} 1)$ was .43 .

As recommended (Spirtes et al. 1998), we also tested alternative models to investigate the robustness of our original model. In a first alternative model (model 1b, not shown in figure), we explored whether pain-related fear at baseline has a direct effect upon pain severity and disability at follow-up. This was done by designing a model without NA at baseline (t0) and at follow up (t1), and without pain-related fear (t1) at follow-up. The goodness-of-fit statistics indicated an acceptable fit $\left(\chi^{2}(2)=3.89, p>.05\right.$, RMSEA $=.05$, CFI $=.99, \mathrm{GFI}=.99$ and AGFI $=.97, \mathrm{CAIC}=95.69)$. The standardized coefficients of this model, revealed a direct effect of pain-related fear at baseline (t0) upon disability at follow-up (t1) $(\beta$ $=.08, p=.01)$. The path between pain-related fear at baseline (t0) and pain-severity at follow (t1) up failed to reach conventional levels of significance $(\beta=.05, n s)$. These two relations are added in dotted lines in Figure 1S.

In a second alternative model (model 1c), we tested whether pain-related fear may be better conceived of as the result of pain severity. To address this issue, we switched the position of pain-related fear with the position of pain severity at baseline and at follow up of model 1a. This alternative model is shown in Figure 1 and resulted in an acceptable fit, $\mathrm{RMSEA}=.05, \mathrm{CFI}=.99, \mathrm{GFI}=.98, \mathrm{AGFI}=.96$ and $\mathrm{CAIC}=183.33$, except for the Chi Square which was significant, $\chi^{2}(14)=27.98, p<.05$. Overall, fit indices of this model were better than those of model 1a (see Table 1S). The standardized indirect effect of pain severity (t0) on pain-related fear (t1) was .29. The standardized indirect effect of pain severity (t0) on disability ( $\mathrm{t} 1)$ was .55. The standardized indirect effect of pain-related fear ( $\mathrm{t} 0)$ on social disability (t1) was .20.

In a third alternative model (model 1d), we explored whether pain severity at baseline has a direct effect upon pain-related fear and disability at follow up. This was done by designing a model without NA at baseline (t0) and at follow up (t1), and without pain severity (t1) at follow up. The goodness of- fit statistics indicated an acceptable fit $\left(\chi^{2}(2)=7.67, p=\right.$ $.022, \mathrm{RMSEA}=.08, \mathrm{CFI}=.99, \mathrm{GFI}=.99$ and $\mathrm{AGFI}=.95, \mathrm{CAIC}=99.47)$. The standardized coefficients of this model, revealed a direct effect of pain severity ( $\mathrm{t} 0)$ at baseline upon disability (t1) at follow up $(\beta=.26, p<.001)$. The path between pain severity ( $\mathrm{t} 0)$ at baseline and pain-related fear (t1) at follow up was significant $(\beta=.12, p=.005)$. These two relations are added in dotted lines in Figure 1.

In a fourth alternative model (model 1e), we tested whether NA may be better 
conceived of as a consequence of pain-related fear. We switched the position of NA with the position of pain-related fear of model 1a. Analysis revealed an unacceptable model fit: $\chi^{2}(14)$ $=131.06, p<.001, \mathrm{RMSEA}=.14, \mathrm{CFI}=.92, \mathrm{GFI}=.94, \mathrm{AGFI}=.83$ and $\mathrm{CAIC}=286.42$, indicating that NA is not a direct consequence of pain-related fear.

\section{DISCUSSION}

We tested the validity of the fear-avoidance model using path analysis in a sample of employees with LBP at baseline and at follow up. The results can be readily summarized. First, analysis of our original model (model 1a) revealed that pain-related fear at baseline predicted pain and disability at follow-up, albeit indirectly ${ }^{1}$. When its direct effects were tested (model $1 b)^{2}$, there was only a weak effect of pain-related fear at baseline upon social disability at follow up, and no effect upon pain severity at follow up. Second, the effects of pain-related fear may not be accounted for by a disposition to experience negative affect (model 1e). Third, the model in which pain-related fear is a consequence of pain severity (model 1c) had a better fit than our original model (model 1a) in which pain-related fear is an antecedent of pain severity. In this model both pain-related fear and pain severity at baseline predicted disability at follow up indirectly. The prospective effects of pain severity were the most pronounced. Furthermore, when the direct effects are tested (model 1d), there was a significant effect of pain severity at baseline upon pain-related fear at follow-up and upon disability at follow-up.

To further examine the validity of the fear-avoidance model, we cross-validated similar models in study 2 with young employees. An important difference with study 1 is that participants in study 2 only included participants who had no (or a limited) experience of LBP during the year preceding baseline measurement, but developed LBP at follow up. Using this strategy, this study allows investigating the development instead of the maintenance of LBP problems.

\section{STUDY 2}

\footnotetext{
${ }^{1}$ The models tested include (partially) cross-sectional and longitudinal data. One should be careful to interpret the indirect effects as causal (Cole and Maxwell 2003)

${ }^{2}$ All direct effects are based on prospective data.
} 


\section{MeTHOD}

\section{PARTICIPANTS AND PROCEDURE}

Data of the Belcoback project were used (Van Nieuwenhuyse et al. 2004; Van Nieuwenhuyse et al. 2006). Participants in this prospective cohort study were young workers (not older than 30 years) with limited antecedents of LBP (i.e., they had been free of episodes of LBP that lasts seven or more consecutive days during the twelve months before intake in the study). Employees were recruited from health care institutions and distribution companies. Details about research objectives, recruitment of participants, and prospective results are reported elsewhere (Van Nieuwenhuyse et al. 2004; Van Nieuwenhuyse et al. 2006). A total of 851 workers who were employed in their function for at least two months responded at baseline. At one year follow-up, 716 workers returned the questionnaire (resulting in a response rate of $84 \%$ ). From this sample, we selected 266 respondents who developed LBP at follow-up. LBP was defined as having experienced LBP more than one day during the past year. After list-wise deletion, a study sample of 238 (mean age $=26.59, S D=2.64$ ) remained. All employees signed an informed consent. The study protocol was approved by the Commission for Medical Ethics appointed by the College of Physicians $n^{\circ} 117$ at the External Service for Prevention and Protection at Work (IDEWE, Leuven, Belgium).

\section{MEASURES}

Participants completed a battery of questionnaires assessing sociodemographic information, negative affect and pain-related fear, both at baseline and 12 month follow-up. Because participants had a limited experience of low back pain at baseline, pain severity and pain-associated disability were only measured at follow-up.

Negative affect was measured at baseline and at follow-up with the same instrument as in Study 1, i.e. the Positive and Negative Affect Scale (PANAS; Watson et al. 1988).

Pain-related fear at baseline was assessed by the modified version of the Tampa Scale for Kinesiophobia (TSK-G) which was specifically developed for pain free individuals (Houben et al. 2005). It consists of 12 items to be rated on a 4-point scale with scoring alternatives ranging from 'strongly agree' to 'strongly disagree' (sum-score range 12-48). The psychometric properties of the TSK are excellent (Houben et al. 2005). Pain-related fear at follow-up was measured with the same instrument as in study 1, i.e. the the Tampa Scale for 
Kinesiophobia (TSK; (Kori et al. 1990; Goubert et al. 2004b; Roelofs et al. 2004).

Pain severity was only assessed at follow-up. It was assessed with the same 11-point NRS's (1-10) as used in study 1 (Von Korff et al. 1992), registering present, worst and average LBP severity in the past 12 months. We intented to use a mean sum score of these three items as index of pain severity (Von Korff et al. 1992). However, preliminary analyses revealed an unusually high number of missing values on the item assessing present LBP severity (about 63\%). We decided to drop this item from further analyses, and to calculate a mean sum score based on the two remaining items, i.e., worst and average BP severity in the past 12 months. However, in study 1 pain severity was calculated on all three items. To investigate whether the deletion of the item has an impact on our results, we reanalyzed the data of study 1 with omission of the item assessing present LBP pain. These analyses revealed no difference than those reported for study 1.

Pain-related disability was assessed by three items (Von Korff et al. 1992) using an 11-point NRS (' $0=$ no hindrance experienced' and ' $10=$ impossible to perform activities'): "To what extent did your low back pain interfered with your daily activities since the start of the study (about 12 months ago)?”; "To what extent did your low back pain changed your ability to take part in recreational, social and family activities since the start of the study (about 12 months ago)?"; and "To what extent did your low back pain change your ability to work (including housework) since the start of the study (about 12 months ago)?". We used a mean score.

\section{STATISTICAL ANALYSES}

The statistical approach was similar to the one described in study 1 .

\section{RESULTS}

\section{PRELIMINARY ANALYSES}

We used listwise deletion of variables; 238 participants had valid values on all variables and were included in the path analyses. Table 2 displays means, standard deviations, Cronbach's alphas and Pearson's product moment correlations for the variables in study 2. Total scale scores were internally consistent with Cronbach's alphas varying from $\alpha=.70$ to $\alpha$ $=.92$. The scores for NA at baseline and at follow-up were similar to the levels found in study 
1. Levels of pain-related fear, as measured by the modified TSK-G were high at baseline (Houben et al. 2005). Pain-related fear as measured with TSK at follow-up was however low (Goubert et al. 2004b).

Overall, the pattern of correlations was as expected (see Table 2), with pain-related fear at follow-up positively associated with baseline fear and with pain severity and disability at follow-up (with coefficients varying between .23 and .47 in absolute terms). The most pronounced correlation was found between pain severity and disability, suggesting that more severe pain interfered with more daily social activities. The least pronounced correlations were found for NA. Most of the correlations with NA were not significant.

\section{MODEL TESTING}

We decided to cross-validate the best fitting model of study 1 . This was model 1c, in which pain-related fear is a consequence of pain severity. However, an identical model could not be tested because participants at baseline had no pain- and pain-associated disability at baseline. Therefore model 1c was modified by dropping pain severity and disability at baseline, resulting in model 2a (as depicted in Figure 2). The fit statistics are shown in Table $1 \mathrm{~S}$ and indicate an excellent model fit: $\chi^{2}(7)=8.31, p>.05, \mathrm{RMSEA}=.03, \mathrm{CFI}=.99$, GFI $=.99$, $\mathrm{AGFI}=.96$ and CAIC $=98.98$. The standardized indirect effect of pain-related fear ( $\mathrm{t} 0)$ on disability (t1) was .12.

Alternative models were also tested. In a first alternative model (model 2b), painrelated fear was designed as an antecedent of pain severity. This was done by switching the position of pain-related fear with pain severity. Goodness-of-fit statistics indicated an acceptable fit: $\mathrm{RMSEA}=.08, \mathrm{CFI}=.97, \mathrm{GFI}=.98, \mathrm{AGFI}=.93$ and CAIC $=108.66$, except for the Chi Square which was significant $\chi^{2}(7)=17.99, p<.05$. The fit indices of model $2 b$ were overall worse than those of model $2 \mathrm{a}$, suggesting that pain-related fear is better conceived as a consequence than as an antecedent of pain severity.

In a second alternative model (model 2c) NA was designed as a consequence of painrelated fear. This was done by switching the position of NA with the position of pain-related fear in model 2a. Analysis revealed an unacceptable model fit: $\chi^{2}(7)=38.21, p<.001$, $\mathrm{RMSEA}=.14, \mathrm{CFI}=.90, \mathrm{GFI}=.95, \mathrm{AGFI}=.85$ and $\mathrm{CAIC}=128.88$.

\section{DISCUSSION}


Using the data of workers who developed LBP at follow-up, we were able to crossvalidate a similar FA model as developed in study 1. An identical model could not be tested, because in this study participants had no back pain or pain-associated disability at baseline. The results can be readily summarized. First, as in study 1 , the model in which pain-related fear is a consequence of pain severity had a better fit than the model in which pain-related fear is conceived of as an antecedent of pain severity. Second, and in line with study 1 , the effects of pain-related fear can not be equated with the effects of the general disposition to experience negative affect.

\section{GENERAL DiscuSSION}

Using path analyses we tested the fear-avoidance (FA) model in two independently designed studies. The results of both studies were similar. First, pain-related fear at baseline predicted pain-severity and disability at follow-up, albeit indirectly. The direct effect of painrelated fear at baseline upon pain severity at follow up was not significant. The direct effect of pain-related fear at baseline upon disability was significant but of small effect size. Second, pain-related fear was better modelled as a consequence than as an antecedent of pain severity. Third, pain-severity at baseline showed to strongly predict both pain-related fear and disability at follow-up. Fourth, negative affectivity (NA) had no or neglectable effects upon pain severity or disability.

Overall, the pattern of results corroborates the idea that pain-related fear plays a significant role in explaining disability (Vlaeyen et al. 1995; Crombez et al. 1999b; Fritz et al. 2001; van den Hout et al. 2001; Waddell 2004; Boersma and Linton 2005). Particular strengths of our two studies are their prospective nature and the use of path analyses. In workers with ongoing back pain, the analysis revealed that the associations as established in the FA model are partially maintained from baseline to follow-up. In pain-free young workers who developed LBP later on, the analysis also revealed a good fit of the FA model. The models of both studies had an acceptable fit, and the findings are highly similar.

Some results warrant further discussion. Although our results indicate a role for painrelated fear in predicting social disability, its role in predicting pain severity was largely unsubstantiated. Indeed, pain-related fear was better conceived of as a consequence of painseverity, rather than as its antecedent. The observation that pain-related fear in pain-free individuals (study 2) did not predict pain later on is in line with the fear-avoidance model. According to the FA- model, pain-related fear does not initiate or cause LBP, but comes into 
play once LBP is experienced. However, the finding that pain-related fear in participants experiencing pain (study 1) had no direct effect upon pain severity, was not expected. First, according to the FA-model, pain-related fear induces a hypervigilance for pain, which is expected to amplify the pain experience (Vlaeyen and Linton 2000). Our findings are not in line with this view. It is possible that the hypervigilance hypothesis of the FA model needs further experimental research. Indeed, there is as yet no experimental evidence that hypervigilance directly amplifies pain (Crombez et al. 2005). Second, according to the FAmodel, pain-related fear leads to a pattern of safety-seeking behaviours including avoidance and escape. Avoidance behaviours, are likely to result in reduced activity levels and lowered fitness (deconditioning) which may render the performance of physical tasks more painful (Verbunt et al. 2003). However, the evidence showing an association between pain-related fear, lowered fitness levels and pain is weak (Wittink et al. 2000; Verbunt et al. 2005).

Although our results suggest that it is more parsimonious to view pain-related fear as a consequence of pain severity, this does not imply that its effects are redundant to those of pain severity. Indeed, in study 1 pain-related fear predicted disability, beyond the effect of pain severity. In study 2, pain-related fear was even predictive of disability in a sample that did not experience LBP at baseline. There may be at least two explanations for this finding. First, pain-related fear is known to instigate avoidance behaviour (Crombez et al. 1998; Pfingsten et al. 2001; Vlaeyen et al. 1995). The avoidance of physical activities that are expected to harm or hurt may lead in itself to a decreased ability to perform daily activities and social roles. This avoidance behaviour may easily persist because few opportunities exist to correct the (erroneous) expectations and beliefs about pain and injury (Vlaeyen and Linton 2000; Goubert et al. 2005). Second, pain-related fear is known to be related to catastrophic ruminations about pain and more attention to pain (Crombez et al. 1999a; Grisart and Plaghki 1999). These cognitive events demand attention in themselves, and may interfere with cognitive and social functioning. It is reasonable to assume that this pattern of behaviour comes into action once a LBP episode is experienced (Sieben et al. 2005).

Of further importance are our findings about the role of negative affectivity (NA). The general disposition to experience negative affect, has often been linked to more severe pain. According to the theory of Watson and Pennebaker (1989), individuals high in NA are thought to be more inclined to detect bodily sensations, and to be more likely to interpret them as painful and pathological. There are also some studies that show an association between NA and pain perception (Pfingsten et al. 1997). However, evidence for this view has been weak in other studies (see also Goubert et al. 2004a). Also in our studies, the effects of NA upon pain 
severity or pain disability were absent or neglectable. Our results further indicate the (unique) predictive value of pain-related fear above and beyond NA. Our findings clearly argue against the thesis that pain-related fear is only another measure of NA, and that the effects of both variables are interchangeable. A direct test of this thesis was performed in our studies: the position of NA was switched with the position of pain-related fear. In both studies this resulted in an unacceptable fit of the models. It may be better to conceive NA as a vulnerability factor: NA predisposes individuals to experience pain-related fear when in pain (Goubert et al. 2004a).

Although we have found in a previous study in patients with chronic pain problems that pain-related fear is more disabling than pain itself (Crombez et al. 1999b), the results of the present studies suggest otherwise. In both studies the impact of pain severity upon disability was larger than the effect of pain-related fear. Of course, this might be due to methodological differences (e.g., the operationalisation of pain severity). However, it is helpful to remember that pain is a hardwired sign of bodily threat, and that it is designed to interrupt attention, and to interfere with ongoing activities (Eccleston and Crombez 1999).

In terms of clinical implications, the study results suggest that in individuals suffering an episode of low back pain, both pain severity and pain-related fear are factors affecting daily and social activities. Interventions aimed at preventing LBP disability should focus on reducing pain severity and pain-related fear, also in the acute stage of LBP. This poses a real challenge to primary care health providers as trying to reduce fear levels even when pain remains stable simultaneously is not easy. Population-based interventions aimed at changing beliefs about the harmfulness of activities have shown their merits (Buchbinder et al. 2001), but their application in the workplace needs to be explored.

Strengths of this study are the path analytic approach and its prospective character. Indeed, a longitudinal research allows for more firm inferences regarding the directionality of the relationships found (Holmbeck et al. 2006 ). The overall pattern of results support the FA model (despite the fact that some of our findings argue for further refinements). We were able to obtain an acceptable fit for our FA models in study 1, and were able to cross-validate similar models in study 2 . To our knowledge, this is the first study that has tested the structural relationships between FA variables using a prospective design.

There are also some limitations. First, due to the particular design of study 2, some measures could not be assessed at baseline. Because the sample of this study were young (< 30 years) and pain-free workers, we had no measures of pain severity or disability at baseline. Second, the models we have tested were more appropriate in predicting pain-related fear and 
disability than in predicting pain severity. This is in line with the available literature showing that the role of psychosocial variables in the onset of pain is still inconclusive (Crombez et al. 2009; Macfarlane et al. 2009). More research is needed that focuses upon how and when psychosocial variables come into play and dynamically interact once pain is experienced. These studies can best be conceived in an expanded affective-motivational perspective of pain-related fear, with a prominent focus on behavior in context (Eccleston and Crombez 2007; Van Damme et al. 2008; Vlaeyen et al. 2009; Van Damme et al. 2010). A third limitation lies in the reliance on self-reports. This may have increased the likelihood of recall bias or confound among measures (van Poppel et al. 2002), but the self-report of pain and disability remains an important and well-validated research method (Deyo and Diehl 1983).

\section{ACKNOWLEDGEMENTS}

Study 1 was supported by an EU Interreg II grant: EMR. INT2.97.10.V.061. The authors like to thank H. van den Heuvel, M. Goossens, S. Beurskens, and A. Leclerc for their helpful suggestions throughout the design and realization of the study.

Study 2 was supported by the Belgian Federal Office for Scientific, Technical and Cultural Affairs (OSTC), projects PS/93/25, PS/12/26, PS/01/27. The authors like to thank the other co-workers from the Belcoback study group for their contribution to data collection and data processing: P. Somville, A. Burdorf, G. Verbeke, K. Johannik, O. Van den Bergh, R. Masschelein, D. Pirenne, E. Persijn, A. Leys and L. Moors. 


\section{REFERENCES}

Arbuckle JL. Amos 5.0 update to the Amos user's guide. Chicago, IL: SPSS; 2003.

Arbuckle JL, Wothke W. Amos 4.0 user's guide. Chicago, IL: SPSS; 1995-1999.

Bentler PM. Comparative fit indices in structural models. Psychol Bull 1990;107:238-246.

Boersma K, Linton SJ. Expectancy, fear and pain in the prediction of chronic pain and disability: A prospective analysis. Eur J Pain 2005;10:551-557.

Bollen KA, Long JS. Testing Structural Equation Models. Newbury Park, CA: Sage; 1993.

Browne MW, Cudeck R. Alternative ways of assessing model fit. In: KA Bollen, JS Long (eds.), Testing structural equation models (136-162). Newbury Park, CA: Sage; 1993.

Buchbinder R, Jolley D, Wyatt M. Population based intervention to change back pain beliefs and disability: three part evaluation. Brit Med J 2001;322:1516-1520.

Burnham KP, Anderson DR. Model selection and inference: a practical information-theoretic approach. New York: Springer-Verlag, 1998.

Byrne BM. Structural equation modeling with Amos: Basic concepts, applications and programming. New Jersey, NJ: Lawrence Erlbaum Associates, Inc.; 2001.

Closs SJ, Barr B, Briggs M, Cash K, Seers K. A comparison of five pain assessment scales for nursing home residents with varying degrees of cognitive impairment. J Pain Symptom Manage 2004;27:196-205.

Cole DA, Maxwell SE. Testing mediational models with longitudinal data: questions and tips in the use of structural equation modeling. J Abnorm Psychol 2003;112:558-577.

Cook AJ, Brawer PA, Vowles KE. The fear-avoidance model of chronic pain: Validation and age analysis using structural equation modeling. Pain 2006;121:195-206.

Crombez G, Beirens K, Van Damme S, Eccleston C, Fontaine J. The unbearable lightness of somatisation : a systematic review of the concept of somatisation in empirical studies of pain. Pain 2009;145:31-35.

Crombez G, Eccleston C, Baeyens F, van Houdenhove B, van den Broeck A. Attention to chronic pain is dependent upon pain-related fear. J Psychosom Res 1999a;47:403-410.

Crombez G, Van Damme S, Eccleston C. Hypervigilance to pain: An experimental and clinical analysis. Pain 2005;116:4-7.

Crombez G, Vervaet L, Lysens R, Baeyens F, Eelen P. Avoidance and confrontation of painful, back-straining movements in chronic back pain patients. Behav Modif 1998;22:62-77. 
Crombez G, Vlaeyen JW, Heuts PH, Lysens R. Pain-related fear is more disabling than pain itself: evidence on the role of pain-related fear in chronic back pain disability. Pain 1999b;80:329-339.

Deyo RA, Diehl AK. Measuring physical and psychosocial function in patients with low-back pain. Spine 1983;8:635-642.

Eccleston C, Crombez G. Pain demands attention: a cognitive-affective model of the interruptive function of pain. Psychol Bull 1999;125:356-366.

Eccleston C, Crombez G. Worry and chronic pain: A misdirected problem solving model. Pain 2007;132:233-236.

Fritz JM, George SZ, Delitto A. The role of fear-avoidance beliefs in acute low back pain: relationships with current and future disability and work status. Pain 2001;94:7-15.

Gheldof ELM, Vinck J, Van den Bussche E, Vlaeyen JW, Hidding A, Crombez G. Pain and pain-related fear are associated with functional and social disability in an occupational setting: Evidence of mediation by pain-related fear. Eur J Pain 2006;10:513-525.

Gheldof ELM, Vinck J, Vlaeyen JW, Hidding A, Crombez G. The differential role of pain, work characteristics and pain-related fear in explaining back pain and sick leave in occupational settings. Pain 2005;113:71-81.

Gheldof ELM, Vinck J, Vlaeyen JWS, Hidding A, Crombez G. Development of and recovery from short- and long-term low back pain in occupational settings: A prospective cohort study. Eur J Pain 2007;11:841-854.

Goubert L, Crombez G, Danneels L. The reluctance to generalize corrective experiences in chronic low back pain patients: a questionnaire study of dysfunctional cognitions. Behav Res Ther 2005;43:1055-1067.

Goubert L, Crombez G, Van Damme S. The role of neuroticism, pain catastrophizing and pain-related fear in vigilance to pain: a structural equations approach. Pain 2004a; 107:234-241.

Goubert L, Crombez G, Van Damme S, Vlaeyen JWS, Bijttebier P, Roelofs J. Confirmatory factor analysis of the Tampa Scale for Kinesiophobia: invariant two-factor model across low back pain patients and fibromyalgia patients. Clin J Pain 2004b;20:103110.

Grisart JM, Plaghki LH. Impaired selective attention in chronic pain patients. Eur J Pain 1999;3:325-333.

Grotle M, Vollestad NK, Veierod MB, Brox JI. Fear-avoidance beliefs and distress in relation to disability in acute and chronic low back pain. Pain 2004;112:343-352. 
Holmbeck GN, Bruno EF, Jandasek B. Longitudinal Research in Pediatric Psychology: An Introduction to the Special Issue. J Pediatr Psychol 2006 31:995-1001.

Houben RMA, Leeuw M, Vlaeyen JW, Goubert L, Picavet HS. Fear of movement/Injury in the general population: Factor structure and psychometric properties of an adapted version of the Tampa Scale for Kinesiophobia. J Behav Med 2005;28:415-424.

Jöreskog KG, Sörbom D. Lisrel IV user's guide. Mooresville, IN: Scientific Software; 1984.

Kline RB. Principles and practice of structural equation modeling. New York: Guilford; 1998.

Kori SH, Miller RP, Todd DD. Kinesiophobia: A new view of chronic pain behavior. Pain Management 1990:35-43.

Leeuw M, Goossens ME, Linton SJ, Crombez G, Boersma K, Vlaeyen JW. The fearavoidance model of musculoskeletal pain: current state of scientific evidence. J Behav Med 2007;30:77-94.

Macfarlane GJ, Pallewatte N, Paudyal P, Blyth FM, Coggon D, Crombez G, Linton S, LeinoArjas P, Silman AJ, Smeets RJ, van der Windt D. EULAR evaluation of work-related psychosocial factors and regional musculoskeletal pain. Ann of Rheum Dis 2009;68:885-891.

Marsch HW, Balla JR, McDonals RP. Goodness-of-fit indexes in confirmatory factor analysis: the effect of sample size. Psychol Bull 1988;103:391-410.

Pfingsten M, Leibing E, Franz C, Nargaz N, Hildebrandt J. [The importance of bodily complaints in patients with chronic back pain]. Schmerz 1997;11:247-253.

Pfingsten M, Leibing E, Harter W, Kroner-Herwig B, Hempel D, Kronshage U, Hildebrandt J. Fear-avoidance behavior and anticipation of pain in patients with chronic low back pain: a randomized controlled study. Pain Med 2001;2:259-266.

Pincus T, Burton AK, Vogel S, Field AP. A systematic review of psychological factors as predictors of chronicity/disability in prospective cohorts of low back pain. Spine 2002;27:109-120.

Pollard CA. Preliminary validity study of the pain disability index. Percept Mot Skills 1984;59:974.

Roelofs J, Goubert L, Peters ML, Vlaeyen JW, Crombez G. The Tampa Scale for Kinesiophobia: further examination of psychometric properties in patients with chronic low back pain and fibromyalgia. Eur J Pain 2004;8:495-502.

Sieben JM, Vlaeyen JW, Portegijs PJ, Verbunt JA, van Riet-Rutgers S, Kester AD, Von Korff M, Arntz A, Knottnerus JA. A longitudinal study on the predictive validity of the fearavoidance model in low back pain. Pain 2005;117:162-170. 
Spirtes P, Richardson T, Meek C, Scheines R, Glymour C. Using path diagrams as a structural equation modeling tool. Sociol Method Res 1998;27:182-225.

Swinkels-Meewisse IE, Roelofs J, Verbeek AL, Oostendorp RA, Vlaeyen JW. Fear of movement/(re)injury, disability and participation in acute low back pain. Pain 2003;105:371-379.

Tait RC, Chibnall JT, Krause S. The Pain Disability Index: psychometric properties. Pain 1990;40:171-182.

Van Damme S, Crombez G, Eccleston C. Coping with pain: a motivational perspective. Pain 2008;139:1-4.

Van Damme S, Legrain V, Vogt J, Crombez G. Keeping pain in mind: a motivational account of attention to pain. Neurosci Biobehav Rev 2010;34:204-213.

van den Hout JHC, Vlaeyen JWS, Heuts PHTG, Sillen WJT, Willen AJEHL. Functional Disability in Non-Specific Low Back Pain: The role of Pain-Related Fear and Problem-Solving Skills. Int J Behav Med 2001;8:134-148.

Van Nieuwenhuyse A, Fatkhutdinova L, Verbeke G, Pirenne D, Johannik K, Somville PR, Mairiaux P, Moens GF, Masschelein R. Risk factors for first-ever low back pain among workers in their first employment. Occup Med (Lond) 2004;54:513-519.

Van Nieuwenhuyse A, Somville PR, Crombez G, Burdorf A, Verbeke G, Johannik K, Van den Bergh O, Masschelein R, Mairiaux P, Moens GF. The role of physical workload and pain related fear in the development of low back pain in young workers: evidence from the BelCoBack Study; results after one year of follow up. Occup Environ Med 2006;63:45-52.

van Poppel MN, de Vet HC, Koes BW, Smid T, Bouter LM. Measuring sick leave: a comparison of self-reported data on sick leave and data from company records. Occup Med (Lond) 2002;52:485-490.

Verbunt JA, Seelen HA, Vlaeyen JW, van de Heijden GJ, Heuts PH, Pons K, Andre Knottnerus J. Disuse and deconditioning in chronic low back pain: concepts and hypotheses on contributing mechanisms. Eur J Pain 2003;7:9-21.

Verbunt JA, Sieben JM, Seelen HA, Vlaeyen JW, Bousema EJ, van der Heijden GJ, Knottnerus JA. Decline in physical activity, disability and pain-related fear in subacute low back pain. Eur J Pain 2005;9:417-425.

Vlaeyen JWS, Crombez G, Linton SJ. The fear-avoidance model of pain: We are not there yet. Comment on Wideman et al. "A prospective sequential analysis of the fear- 
avoidance model of pain" [Pain, 2009] and Nicholas "First things first: reduction in catastrophizing before fear of movement" [Pain, 2009]. Pain 2009;146:222-223.

Vlaeyen JWS, Kole-Snijders AM, Boeren RG, van Eek H. Fear of movement/(re)injury in chronic low back pain and its relation to behavioral performance. Pain 1995;62:363372.

Vlaeyen JWS, Linton SJ. Fear-avoidance and its consequences in chronic musculoskeletal pain: a state of the art. Pain 2000;85:317-332.

Von Korff M, Ormel J, Keefe FJ, Dworkin SF. Grading the severity of chronic pain. Pain 1992;50:133-149.

Waddell G. The Back Pain Revolution (2nd edition). Edinburgh: Churchill Livingstone; 2004.

Watson D, Clark LA, Tellegen A. Development and validation of brief measures of positive and negative affect: the PANAS scales. J Pers Soc Psychol 1988;54:1063-1070.

Watson D, Pennebaker JW. Health complaints, stress, and distress: exploring the central role of negative affectivity. Psychol Rev 1989;96:234-254.

Wittink H, Hoskins Michel T, Wagner A, Sukiennik A, Rogers W. Deconditioning in patients with chronic low back pain: fact or fiction? Spine 2000;25:2221-2228. 


\section{Figure Legends}

Figure 1. Path diagram of model 1c showing the relationship between negative affect, pain severity, pain-related fear, and disability for study $1(\mathrm{~N}=429)$. Standardized $\beta$-coefficients and $R^{2}$ values are shown, with $R^{2}$ values shown between parentheses above each variable. ( $\left.\mathrm{t} 0\right)$ $=$ the measures at baseline; $(\mathrm{t} 1)=$ the measures at follow-up. The dotted lines are tested in model 1d. $* p<.05 ; * * p<.001$.

Figure 2. Path diagram of model 2a showing the relationship between negative affect, pain severity, pain-related fear and disability for study $2(N=238)$. Standardized $\beta$-coefficients and $R^{2}$ values are shown, with $R^{2}$ values shown between parentheses above each variable. $(\mathrm{t} 0)=$ the measures at baseline; $(\mathrm{t} 1)=$ the measures at follow-up. $* p<.001$. 


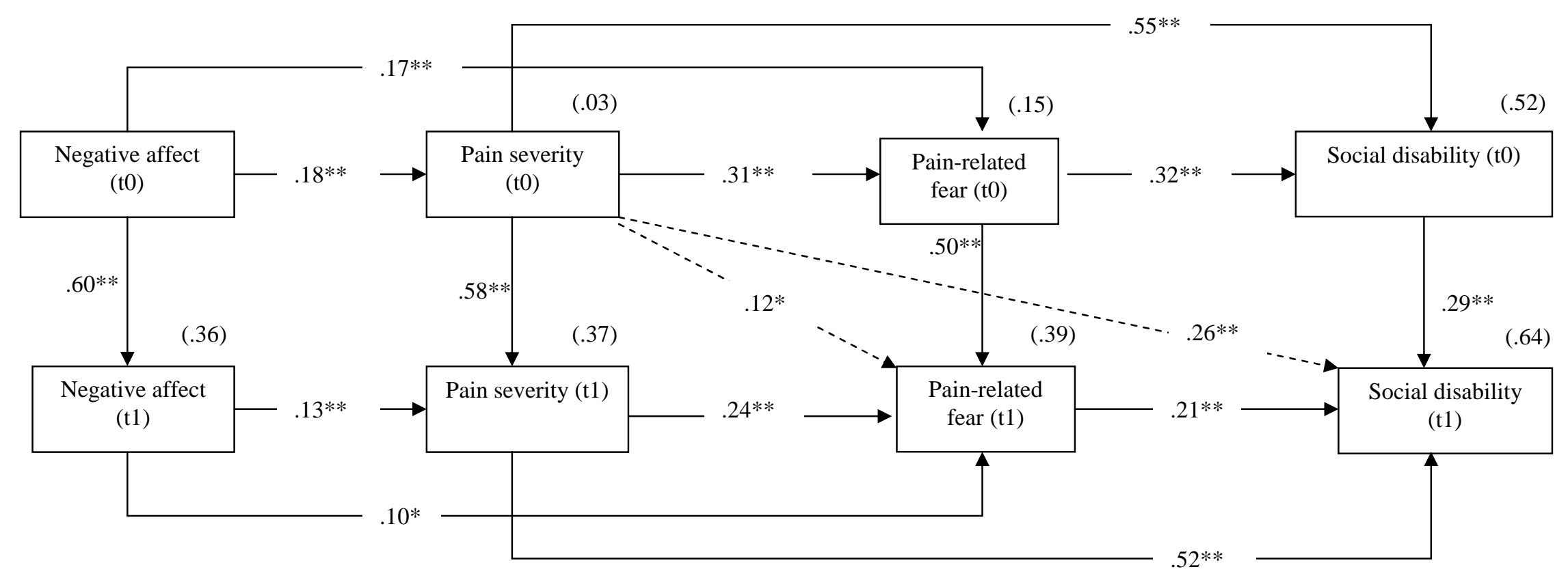




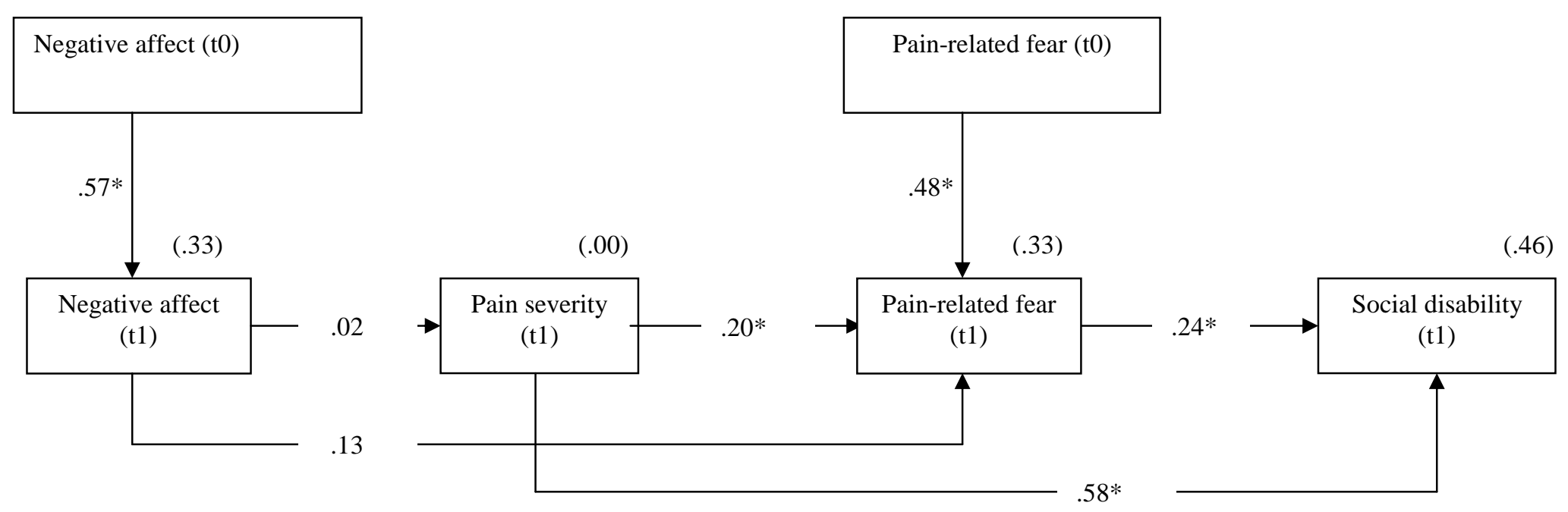


Table 1S

Goodness-of-fit summary for the models tested

\begin{tabular}{cllllll}
\hline & $\chi^{2}$ (d.f.) & RMSEA & GFI & AGFI & CFI & CAIC \\
\hline study 1 $(\mathrm{N}=429)$ & & & & & & \\
model 1a & $37.58(14)^{*}$ & .06 & .98 & .94 & .98 & 192.93 \\
model 1b & $3.89(2)$ & .05 & .99 & .97 & .99 & 95.69 \\
model 1c & $27.98(14)^{*}$ & .05 & .98 & .96 & .99 & 183.33 \\
model 1d & $7.67(2)$ & .08 & .99 & .95 & .99 & 99.47 \\
model 1e & $131.06(14)^{* *}$ & .14 & .94 & .83 & .92 & 286.42 \\
study 2 (N = 238) & & & & & & \\
model 2a & $8.31(7)$ & .03 & .99 & .96 & .99 & 98.98 \\
model 2b & $17.99(7) *$ & .08 & .98 & .93 & .97 & 108.66 \\
model 2c & $38.21(7)^{* *}$ & .14 & .95 & .85 & .90 & 128.88 \\
\hline
\end{tabular}

Note. RMSEA $=$ Root Mean Square Error of Approximation; GFI = Goodness-of-fit Index; AGFI = Adjusted Goodness-of-fit Index; CFI = Comparative Fit Index; CAIC $=$ Consistent Akaike Information Criterion; $* p<$ $.05 ; * * p<.001$. 